\title{
A palavra no palco
}

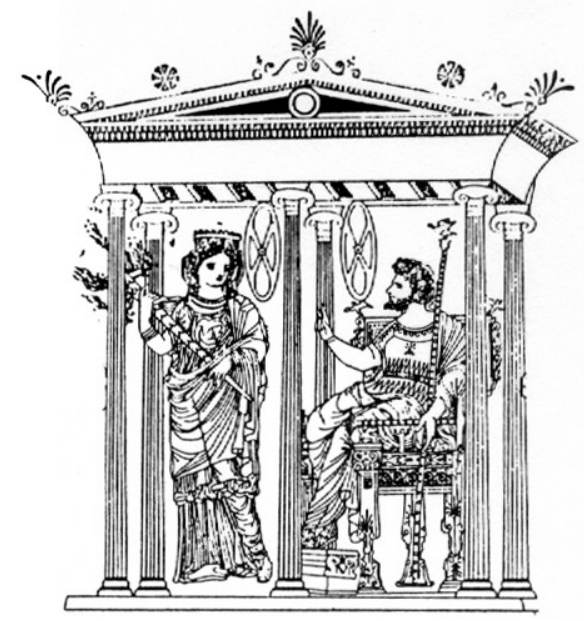

Mariangela Alves de Lima

Sabe-se que a veiculação do trabalho crítico por periódicos, mesmo nos "suplementos" - onde o intuito é também formativo - mantém o compromisso do "gancho", ou seja, procura ligar a atividade ensarstica a um fato específico da vida cultural. Os ensaios publicados no volume $O$ texto no teatro têm essa missão de introduzir o leitor em um terreno desconhecido para facilitar-lhe posteriormente o acesso a uma encenação. $O$ livro compreende ensaios produzidos durante três décadas em paralelismo ao que se exibe nos palcos brasileiros ou em outros lugares do mundo onde o movimento teatral é intenso. São ensaios que cumprem a tarefa de amparar intelectualmente o evento teatral, ampliando sua curta duração temporal e inscrevendo-o no conjunto mais amplo da cultura.

Embora escritos em diferentes períodos e instigados pelo movimento teatral os ensaios contidos neste volume foram agrupados obedecendo à seqüência cronológica do aparecimento dos textos na história do teatro. Formam agora um precioso e raro conjunto onde o leitor pode entrever, através de estudos monográficos, uma perspectiva da evolução da dramaturgia que começa na Grécia e segue até as operações radicais de Heiner Müller sobre a constituição do texto.

Uma vez que se dirigem a um público não-especializado, os escritos de Sábato Magaldi são claros e didáticos, subtraindo ao leitor o imenso esforço de erudição que o autor certamente teve que fazer para dominar matéria tão vasta. Neste tipo de trabalho a agudeza da percepção crítica e a exatidão das palavras devem substituir a proliferação de referências a que o autor poderia recorrer fosse outro o seu círculo de leitores. A circunscrição histórica das peças, suas propriedades estilísticas, as analogias e as conclusões que propiciam, estão firmemente plantadas em exemplos que os textos oferecem, imediatamente visíveis na evidência das obras. Em primeiro plano não está portanto o aparato crítico, mas o próprio texto teatral apresentado de forma a instigar a curiosidade do leitor e a incitá-lo a exercitar sobre essa obra sua inteligência e sensibilidade. Estamos aqui muito longe de uma forma de apreciação crítica que, ainda que fascinante e espertíssima, submerge o seu objeto. Basta dizer que a idéia de evolução histórica que o livro proporciona dispensa uma reconstrução arqueológica do entorno do texto ou uma teoria cênica que unifique essa seqüência. A idéia de progressão resulta de um trabalho no interior do texto teatral, que assimila ou rejeita na sua feitura aquilo que o precede e intui, ou sugere caminhos para as obras que o sucedem.

Há outra razão entretanto para que desses escritos esparsos resulte agora um conjunto tão íntegro. Ligando as diferentes abordagens há firmes postulados críticos que orientam a análise e até mesmo a fruição prazerosa de certas obras. $\mathrm{Na}$ base de toda aferição, justificando a adesão ou a repulsa do autor, está a afirmação da autonomia estética do texto teatral. Um texto se manifesta e se prova pela combinação singular que propõe entre tema, estrutura, densidade de personagens, verossimilhança de situações (quando a situação é importante) e manipulação das palavras. Através do exame dessas
MARIANGELA ALVES DE LIMA é pesquisadora da Fundacem e crítica de teatro do Caderno 2 de $O$ Estado de S. Paulo.

O texto no teatro, Sábato Magaldi. Sấo Paulo, Editora Perspectiva, Coleçăo Es. tudos, $n^{2} 111,482 \mathrm{pp}$. 


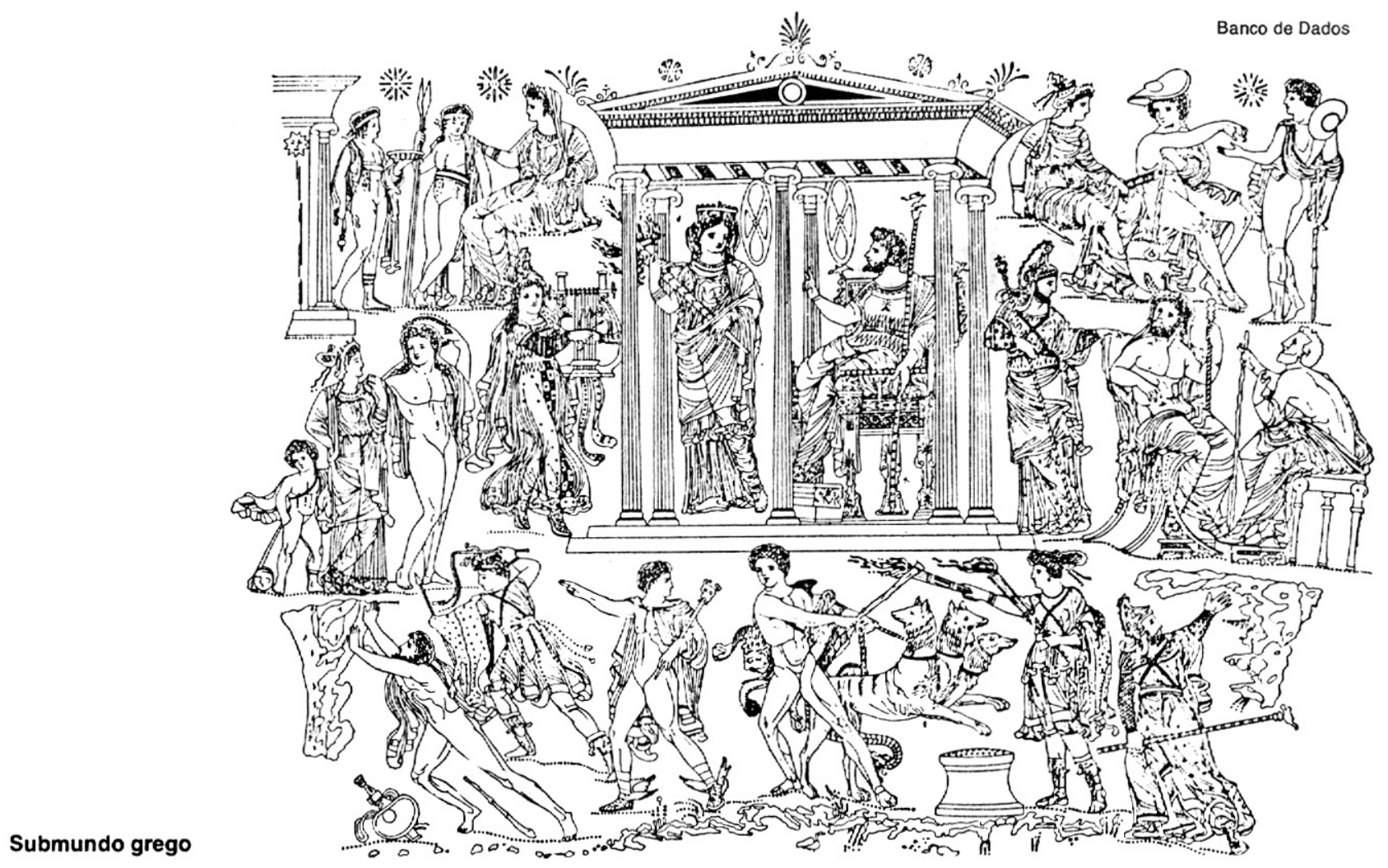

relações internas o crítico chega ou a um juízo de valor ou a uma conclusão sobre o poder de ressonância da obra sobre o mundo contemporâneo. Para enfrentar uma obra não se invoca nada que não possa estar contido na esfera da arte.

Outras afirmações pontuais decorrem dessa postura básica e permitem ao leitor identificar a firmeza do crítico nessa travessia por estilos e épocas tão diversos. São mínimas, mas muito elucidativas, as aparições pessoais em que o crítico manifesta a sua conviç̧ão. Da Comédia Nova grega extrai para si um corolário que impregna todas as abordagens: "Não importa a intriga em si, mas a forma pela qual o escritor a desenvolve". Sabe desde então o leitor que essa convicção será invocada todas as vezes em que um autor retoma, à sua maneira, um tema recorrente. $O$ "como fazer" tem certamente extraordinária importância em um procedimento crítico que privilegia a abordagem estética.

Se cada peça tem a sua formalização única, 'que é preciso desvendar, é uma decorrência que um único método não sirva a todas as obras. De um autor é preciso aproximar-se através do brilho intencional das frases, de outro através da aparente desorganização da ação, de outro ainda através do exame do substrato psicológico da personagem. Dessa forma elimina-se da crítica o lugar-comum e os autores mais conhecidos reaparecem sob nova luz.

Fica claro também que o crítico prefere a amplitude do instrumental e reconhece que todo o aparato conceitual modifica-se no curso da história ou diante da estonteante excepcionalidade de uma obra, mas que tudo isso não deve resultar em uma suspensão de valores ou na abolição do gosto pessoal. Veja-se esta observação: "Um simples levantamento histórico das exegeses mostra que Le Tartuffe se tem prestado a provas de idéias freqüentemente contrárias, de acordo com o ângulo em que se coloca o observador". Por essa razão "torna-se mais estimulante para o crítico aflorar algumas das ambigüidades da peça, desafiadoras de uma resposta única ou de um ponto de vista definitivo". A flexibilidade do método afasta os escolhos da estética normativa e permite um combate singular com o texto. É o que faz o crítico e é para um embate semelhante que convida o leitor.

É uma forma de aproximação que não se socorre da malha crítica pré-fabricada e que também abole definitivamente os "devaneios impressionistas". Em seu lugar adota-se a observação racional da "aventura da linguagem" e é nessa aventura, e não no trabalho crítico, que podem evoluir em liberdade o sentimentalismo, a irracionalidade, a rigidez, a surpresa, a poesia, o misticismo e, enfim, todos os traços humanos. À crítica compete observar o dinamismo de todas as obras verdadeiramente grandes. É a configuração es- 
tética que permite reconhecer em obras de um passado remoto a capacidade para expressar o novo. O mesmo se aplica a obras contemporâneas em que o crítico distingue minuciosamente na sua feitura, através de um trabalho comparativo, o que herdaram do passado, qual a carga de elementos episódicos e circunstanciais que contêm e em que medida há nelas um germe de transcendência que lhes permitiria abarcar uma sensibilidade mutável.

Um crítico que observa e valoriza nas obras a autonomia da configuração estética e o dinamismo que lhes permite a reproposição deve recusar também um tipo de dramaturgia de mediação, determinada por razões estranhas ao território da arte. Essa dramaturgia, que constitui parte significativa da produção contemporânea, Sábato Magaldi repele com veemência: "A tirania ideológica esterelizou a espontaneidade, o delírio do raciocínio suprimiu a fluidez carnal. As máquinas de pensar, representativas de diferentes maneiras de reagir a um dado, transformam a peça em uma intrincada fantasmagoria".

A observação acima aplica-se a Les sequestrés d'Altona, de Sartre, mas reaparece outras vezes para designar um teatro descarnado, de maior ou menor profundidade filosófica, que ocupa os palcos europeus do pós-guerra. Para esse texto utilitário, ocupado apenas com o contingente, não há muita paciência.

Desde o primeiro momento do livro, nos ensaios sobre o teatro grego, Sábato Magaldi reivindica para o teatro uma concretude que pode traduzir-se pela ação, como quer Aristóteles, ou através de um reforço da consistência interior da personagem como quer o teatro moderno, sendo a mente humana o palco das ações interiores. De qualquer forma a presença do ator impõe ao teatro um limite que o dramaturgo deve observar. Entregue-se ao romance, ao ensaísmo ou às artes plásticas a tarefa de representar as abstrações puras.

Sob esse ponto de vista o que salva a dramaturgia de Bernard Shaw não é a inteligência da sua argumentação, mas antes o fato de que "é apenas em cena que o debate fica em pé". Uma polêmica pode adquirir o estatuto de teatro quando se expressa pela agilidade de um jogo, e a reflexão filosófica terá a mesma regalia quando enraizada no sentimento e na vontade de uma personagem com proporções humanas. É uma concretude onde cabem incontáveis formas de expressão desde que invoquem, para justificar o seu aparecimento, uma "credibilidade superior".

Aos autores incapazes de assimilar essa exigência do teatro reserva-se, mais do que uma crítica, uma legítima admoestação. Vejamos esta, dirigida a Montherland: "A fala, em sua obra, muitas vezes omite o indivíduo que a pronuncia. Desaparece a corporeidade cênica, fenômeno essencial ao teatro. (...) A destilação de idéias em teatro tem um indisfarçável saber de subfilosofia. Parece digesto ao alcance de todos".

Esta é uma firme conviç̧ão do crítico, alicerçada talvez em espetáculos, pois é na encenação, mais do que na leitura, que esse equívoco se confirma. Há um tipo de peça que indubitavelmente provoca no crítico a sensação de que errou de endereço e está em uma sala de conferências ou em liceu para estudantes noturnos. Nesse caso a prova do palco é mais dolorosa que a leitura.

Como lugar de síntese o palco deve proporcionar experiências intensas e concentradas. Por essa razão o crítico não hesita em recomendar ao dramaturgo uma certa transigência em relação à ambição do texto. "Não esqueçamos também que uma boa obra, para caber nos limites de um espetáculo, reclama (e não há aqui paradoxo) certo grau de mediocrização. (...) Um dramaturgo consciente de seus recursos e das suas limitaçōes precisa encontrar a equivalência da análise romanesca numa síntese poética, que em nada lhe é inferior como resultado artístico."

\section{Uma Mitologia Particular}

Observadas essas condições que dizem respeito à natureza do fenômeno teatral, o livro aprecia com indisfarçado prazer os experimentos que, a partir da segunda metade do século XIX, alteram princípios da poética aristotélica e integram ao palco todas as novidades do espírito humano. Na segunda parte do livro, "De Jarry a Heiner Müller", a análise enfatiza que as transformaçōes dos recursos expressivos do texto nascem antes de uma ampliação da consciência, de percepçōes renovadas do homem e do mundo, do que de opçōes formalistas. O prinćpio que impulsiona o surgimento de obras realmente inovadoras não e portanto o anticonvencionalismo, mas um desejo real de subversão do estabelecido. Nenhum deslumbramento novidadeiro poderia atravessar essa postura crítica tão serena. 
A contraface desse teatro que mira sempre o mais adiante é o texto teatral que reconhece perfeitamente o limite do palco e erige-o como uma convenção eterna. É o tipo
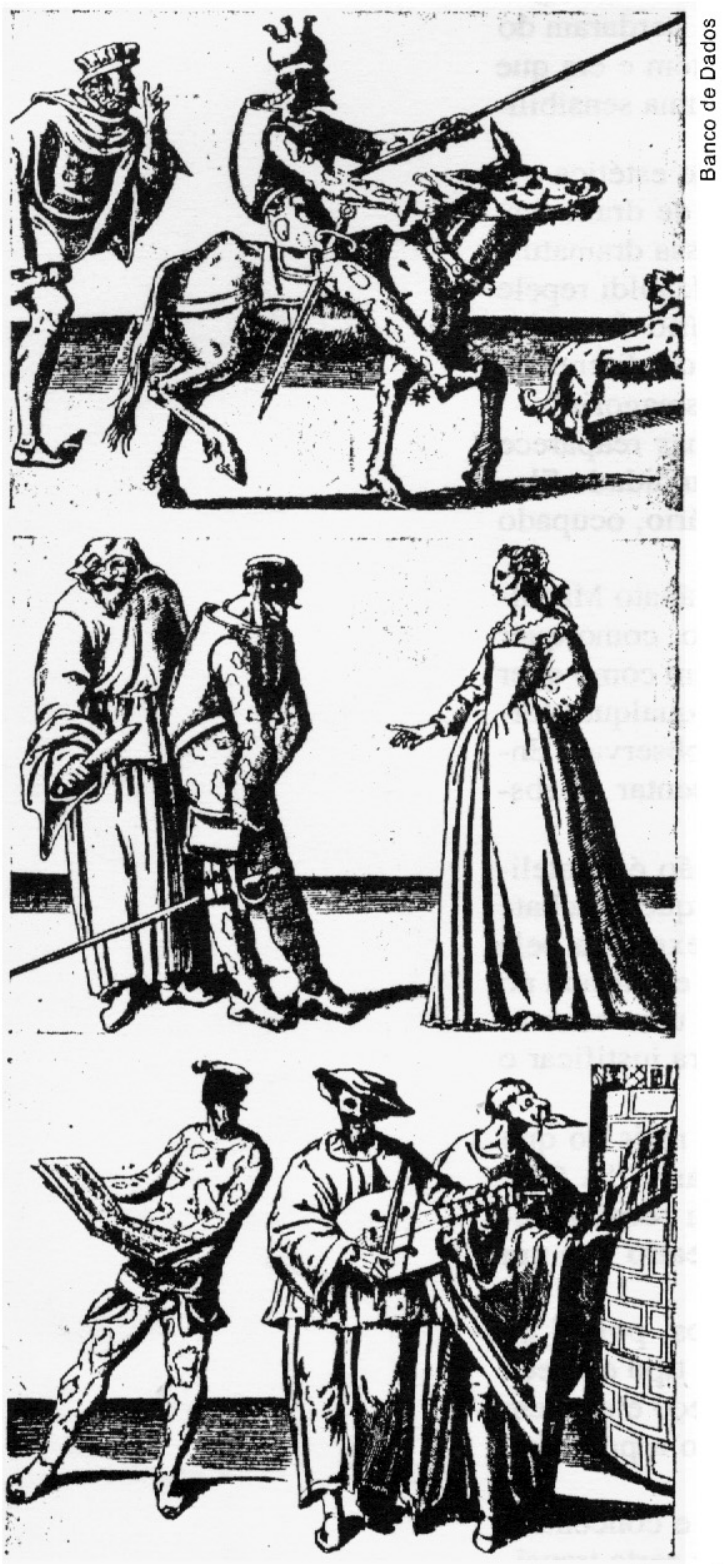

de texto que preenche os brancos de uma estrutura fixa com ações perfeitamente encadeadas, réplicas exatas e um matemático paralelismo presidindo a urdidura da trama. O playwriting, útil talvez para quem tem muito a dizer, mascara irremediáveis platitudes. Aos alunos aplicados da peça bem-feita como Osborne, Robert Anderson ou Anouilh, o crítico reserva acerbos comentários. Talvez porque o labor aplicado desses autores induza ao erro, sugerindo ao espectador que encontrou ali mais do que o que realmente lhe foi oferecido. Ao lado desse engano Sartre, com a sua generosa desproporção, está mais próximo da natureza e do desígnio do teatro do que esses autores que se debruçam apenas sobre um mecanismo perfeito e vazio.

Resta observar que a firmeza de princípios críticos não resulta em uma apreciação equânime de todos os textos abordados. Faz-se justiça às suas qualidades próprias e ao que representam como sedimentação histórica do discurso teatral. Mas há ensaios que testemunham uma paixão pessoal do crítico e que ele, por uma questão de honestidade, faz questão de deixar claro que se trata de um bem intransferível. "Há obras que, até certo ponto independentemente do seu valor objetivo, compōem a nossa mitologia particular e nos falam como confidências sempre renovadas. (...) O juízo crítico nos levaria a admitir outras obras de igual ou superior mérito, de importância maior na história literária, mas esses trabalhos apresentam ressonâncias especiais, encontram-se com a nossa sensibilidade, de forma que gostaríamos de tê-los escrito."

Alguns trabalhos deste livro são fruto de uma ligação mais forte não apenas com o texto teatral, mas com certos temas da história do teatro. Faz parte desse repertório afetuoso o ensaio sobre a commedia dell'arte onde se alia ao rigor de uma informação exata e minuciosa um poder evocativo que presentifica para o leitor a graça e liberdade das máscaras.

Também os quatro ensaios dedicados a Molière revelam aos poucos uma intrincada complexidade de conteúdos mobilizados para que da experiência do texto molieresco possa resultar a apreensão da "imagem secreta e incômoda do homem, despindo-o de insatisfatórias idealizações". Do estudo sobre Molière se desprendem categorias fundamentais para a compreensão da modernidade: a intencional mescla de gêneros, a relação entre o psicológico e o macrocosmo social, a instauração do efeito cômico pela disjunção entre essência e aparência e a intromissão na representação artística de uma forma de realismo que dá testemunho, não da superfície da vida, mas de uma "funda noção da miséria humana". Apreensões exatas e profundas de um crítico que se debruça

Gravuras aludindo à commedia dell'arte, cuja origem data de meados do séc. XVI sobre a obra não para decifrá-la, mas para enfatizar o seu imenso poder analógico.

Outro momento especial do livro é o ensaio sobre Woyzeck, de Büchner. O movimento para o exame lúcido da obra reproduz até certo ponto a "vertigem" que ela representa. Atribuindo a essa obra a "beleza perene das obras inacabadas", a análise da estrutura de composição é secundária. A crítica mergulha em direção ao significado maior do texto, ao desejo de totalização que o motiva e que deve levá-lo a abarcar a condição humana. Reconhecemos através desse método de abordagem a moderna concepção do trágico de onde nascem outras formulações contemporâneas: a liberdade possível sob um céu despovoado. Cabe ao teatro, sinteticamente, representar esse ponto.

Outras preferências se insinuam com igual vigor (O’Neill, Brecht, Ionesco e Arthur Miller) comprovando que a preferência não se escora em uma determinada linha temática ou estilística. Nasce antes do reconhecimento de que as obras maiores contêm um impulso ascendente em direção ao reconhecimento do homem.

Insinua-se dentro deste livro outro livro. A medida que baliza as diferentes cosmogonias que o teatro constrói no tempo é, para o crítico, a questão que emerge na Orestíada, no momento em que Ésquilo esculpe "o primeiro homem livre da literatura dramática". Uma vez que o propósito destes ensaios é situar as obras, não há espaço para que a questão se aprofunde. 